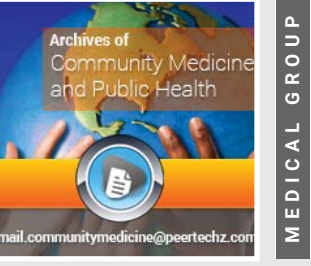

\section{Implications for general practitioner of evolution of incidence rates of COVID-19 breakthrough infections in vaccinated people as of December 2021 with the highest spike of infections of the entire pandemic}

\section{Jose Luis Turabian*}

Specialist in Family and Community Medicine, Health Center Santa Maria de Benquerencia. Regional Health Service of Castilla la Mancha, (SESCAM), Toledo, Spain
Received: 10 January, 2022

Accepted: 20 January, 2022

Published: 21 January, 2022

*Corresponding author: Jose Luis Turabian, Specialist in Family and Community Medicine, Health Center Santa Maria de Benquerencia. Regional Health Service of Castilla la Mancha, (SESCAM), Toledo, Spain, Tel: 34-925230104; E-mail: jturabianf@hotmail.com

ORCID: https://orcid.org/0000-0002-8463-171X

Keywords: COVID-19; SARS-CoV-2; Vaccination; Breakthrough infection; Attack rate; General practice

Copyright License: (c) 2022 Turabian JL. This is an open-access article distributed under the terms of the Creative Commons Attribution License, which permits unrestricted use, distribution, and reproduction in any medium, provided the original author and source are credited.

https://www.peertechzpublications.com

\section{Check for updates}

\begin{abstract}
From the extension of the COVID-19 vaccination in December 2020 to the end of the summer of 2021, cases of breakthrough Infection in vaccinated people were rare and their attack rate was low $(0.01 \%-5.5 \%)$. Of course, in light of the increase in vaccination rates, breakthrough Infection in vaccinated people progressively could represent the majority of all COVID-19 cases. But at the end of December 2021, the world registered the highest number of CoVID-19 infections in a week. Just a few months ago, the evolution that seemed reasonable was thought to be the elimination of the pandemic. But Delta, and Omicron after, arrived; and we weren't expecting them. The latter clearly evades immunity against vaccine-based infection, and breakthrough infections are becoming more common. This situation causes certain effects at the community level and has implications for the general practitioner: 1 . Availability of vaccines has brought about a change that, when they began to be applied, seemed much more promising than it is currently; 2. This context may increase denial regarding COVID-19 vaccines; 3 . Vaccination has contributed to an appreciable reduction in the number of serious and critical clinical cases; 4 . Attack rates in vaccinated will increase as the proportion of vaccinated increases; 5 . The importance of booster doses when immunity falls; 6 . Incidence rates at the community level and official diagnostic tests will no longer be important.
\end{abstract}

\section{Introduction}

The widespread availability of coronavirus disease (COVID-19) vaccines was the most exciting medical event in healthcare, in 2021 [1]. So far we know that the majority of COVID-19 patients after vaccination tend to have a mild illness or even remain asymptomatic [2]. It must be taken into account that in view of the increase in vaccination rates, where these are high, the breakthrough cases progressively represent the majority of all COVID-19 cases. In the absence of third doses, the breakthrough cases remain relatively mild. But, decreased immunity or further evolution of the virus could also mean that breakthrough cases worsen, making booster injections essential [3-5].
Data support that Severe Acute Respiratory Syndrome Coronavirus 2 (SARS-CoV-2) vaccines induce immunity: protection against any SARS-CoV-2 infection decreases during the first months (but protection against serious infections remains relatively durable). High levels of preexisting antibodies are probably required to prevent initial infection, while prevention of severe disease can be achieved by subsequent immune enhancement by anamnestic antibodies by memory cells and activation of cell-mediated antiviral immunity. Thus, the public health implications of preventing SARS-CoV-2 infections, and the current uncertainty about the long-term clinical consequences of COVID-19, favor the use of booster doses [6-8]. 
However, at the end of December 2021, the world registered the highest number of COVID-19 infections in a week (Six and a half million coronavirus infections in a week). The United States registered 1,082,549 new cases of coronavirus on January 4,2022 , a daily figure that had not been reported anywhere in the world during the pandemic [9]. In this way, the previous record, which was set at the end of April 2021, when the focus of the pandemic was in India, was surpassed and, on average, more than 800,000 cases were registered per day. The current rise in cases is concentrated in Europe and North America.

On the European continent, it is about to exceed half a million new cases, on average, per day $[10,11]$. Up to February 15,2022 , an estimated projection of 250,000 COVID-19 daily cases of Omicron spread was made in the worst scenario and 170,000 in the best scenario, in England [12]. Even, that data may be conservative after it was finished writing this. It is impossible to forecast the number of cases; omicron grows exponentially and we will probably never get a forecast right [13].

In this context, this article aims to reflect on this surprising and unexpected evolution of the incidence rates of COVID-19 breakthrough infections in vaccinated people (which instead of decreasing as the proportion of vaccinated increases, they increase exponentially), as well as some repercussions at the general medicine level of this evolution.

\section{Methods}

For the literature review, a pragmatic approach was used that was based on a non-systematic or opportunistic narrative review considered the bibliographic references of selected articles and opportunistic searches on the Internet. This article should be understood as a personal view, based on the author's experience and the literature review as described above.

\section{Discussion}

The surprising evolution of the incidence rate of breakthrough infections in vaccinated people has direct implications at the General Practitioner (GP) level, on which it is desirable to reflect in order to act at the local level (Table 1). The fundamental concepts of general medicine are basic pillars for COVID-19 care: Comprehensiveness and integrality; Continuity; Context and contextualization; Uncertainty; Complexity; Community; Patient-centered Interview; Biopsychosocial Model; Actors and resources/strengths of the patients; Medicalization and technology; Familia; Meaning of Symptoms; Diagnosis and treatment; Concept of health and disease; and Variability. These basic pillars of general medicine apply to the care of COVID-19 give place to key areas of reflection and intervention for the GP [14-16].

\section{We did not expect it}

The painter Ilya Repin painted the picture "They did not expect Him" (1884-1888, oil on canvas, Tetriakov Gallery, Moscow) [17]. To the astonishment of his family, an exiled Russian revolutionary returns to his house without warning. In the painter, he managed to make a masterful study of the different faces of surprise that human beings can put on. Each of the characters reacts differently to the arrival of man. In the same way, the different health actors, planners, politicians, etc., and the population as a whole have been left surprised by the explosive evolution of breakthrough infections in vaccinated people.

Just a few months ago, it was thought that based on reported vaccine efficacy data, as worrisome as breakthrough infections seemed, they were still relatively rare [18]. Until the summer of 2021, reported rates of COVID-19 breakthrough infections in vaccinated people ranged from $0.01 \%$ to $5.5 \%$ (except in one outbreak, where $57 \%$ was found). Thus they were reported rates of $0.01 \%, 0.05 \%, 0.09 \%, 0.2 \%, 0.3 \%$, $0.4 \%, 0.55 \%, 1.5 \%$ and $5.5 \%$, according to geographic location type of people vaccinated (nursing homes, workers health, general population), time since vaccination, predominance of new variants of SARS. CoV-2, inclusion or not of asymptomatic patients, etc [18-32].

\section{The relentless march of Omicron}

On November 26, 2021, the World Health Organization

Table 1: Community-level effects and implications for the general practitioner of the evolution of breakthrough infections incidence rate in vaccinated people.

\section{Community-level effects of evolution of \\ breakthrough infections incidence rate in} vaccinated people

1. Availability of vaccines has brought about a change, but when they began to be applied seemed much more promising than it is being

2. Denial of COVID-19 vaccines

3. Vaccination has contributed to a significan reduction in the number of serious and critica clinical cases

4. Attack rates in vaccinated will increase as the proportion of vaccinated increases

5. The fall of immunity

6. Incidence rates at the community level and official diagnostic tests will no longer be important
Implications for the general practitioner

To be clear about the important results of vaccination. Avoid a unique conclusion; to understand that this "surprise" produces different reactions to the different health actors, planners, politicians, etc. and the population as a whole

Need for persuasive patient-centered advice from the general practitioner leve

The risk of becoming infected only clearly decreases among those with three doses. Need for vaccination of patients with higher risks. The importance does not reside so much in vaccinated (which already seems established that with two doses they notably avoid serious disease, and with three they reduce the risk much more), but with those not vaccinated or vaccinated with a single dose, although also for those where we know that the efficacy of vaccines is lower, such as those over 65 years of age, immunosuppressed and patients with comorbidities

This fact does not imply any failure of the vaccines. You probably really measure your success. Redefine the value and meaning of the incidence rate

Need for vaccine boosters. Rigorously encourage patients to follow the public health standards of masking and social distancing

Rapid antigen tests could be of great help to decentralize the saturation of central services. Provision of tests for the same people to self-detect. Search for family contacts at the local level. Maintenance of the registry of cases and contacts at the GP level to maintain traceability and epidemiological follow-up. The task of attending to Long COVID-19.

Citation: Turabian JL (2022) Implications for general practitioner of evolution of incidence rates of CoVID-19 breakthrough infections in vaccinated people as of Decembe 2021 with the highest spike of infections of the entire pandemic. Arch Community Med Public Health 8(1): 008-012. DOI: https://dx.doi.org/10.17352/2455-5479.000168 
(WHO) named variant B.1.1.529 (omicron) of SARS-CoV-2, first detected in South Africa, as a variant of concern. By November 29, 2021, three days after the WHO announcement, cases of omicron variant infection had already been detected in many other countries [33,34]. The highly transmissible Omicron variant has spread around the world, infected millions of people, and has proven too rapid to detect, even in countries with high vaccination rates.

\section{Availability of vaccines has brought about a change that, when they began to be applied, seemed much more pro- mising than it is being}

Mass vaccination has not served to control community transmission of the virus. Despite the fact that worldwide, vaccination began in December 2020, if pairs of countries with similar epidemiological data are compared, curves with very different vaccine coverage can be observed, which seems to indicate that the vaccine had little impact on the epidemic of SARS-CoV-2 [35]. That is, surprisingly, mass vaccination has not served to control community transmission of the virus [36].

The seemingly reasonable evolution of the elimination of the pandemic (it was accepted that occasional sporadic outbreaks of COVID-19 would inevitably occur, but could be contained quickly, thanks to a comprehensive and effective vaccination program, widespread testing, and a virus with a code relatively stable genetics for which our immune system would generate lasting protection), surprisingly is not being fulfilled. Delta arrived. And then Omicron, and "we weren't expecting it." The latter variant clearly evades immunity against vaccine-based infection, and breakthrough infections are becoming much more common [37].

Vaccine effectiveness has changed dramatically in the Omicron era: booster protection against omicron infection lasts for less time; Third doses or boosters with the Pfizer/BioNTech or Moderna vaccines in those who completed schedules with Pfizer/BioNTech or AstraZeneca provide a protection level against symptomatic infection by the omicron variant of the SARS-CoV-2 virus that falls from $60 \%-75 \%$ after two to four weeks from application to $35 \%-45 \%$ when 10 weeks have passed; this is a more accelerated loss of effectiveness than verified with delta. However, they are still likely to continue to prevent a significant number of hospitalizations and deaths [38].

One study found reduced effectiveness of the BNT162b2 vaccine of $70 \%$ in Omicron vs. $93 \%$ compared to hospitalization for COVID-19; the addition of a booster dose of the vaccine may mitigate this reduction in vaccine efficacy [34]. Another study analyzed the neutralization efficacy of the BNT162b2 vaccine against wild-type SARS-CoV-2 and the beta, delta, and omicron variants; Low neutralization efficacy was found with two doses of the BNT162b2 vaccine against the wild-type virus and the delta variant, evaluated more than 5 months after receiving the second dose, and no neutralization efficacy against the omicron variant. Again, the importance of the third dose of vaccine is clear. However, even with three doses of vaccine, neutralization against the omicron variant was lower (by a factor of 4) than against the delta variant. And the durability of the effect of the third dose of the COVID-19 vaccine has not yet been determined [33].

In this regard, based on an analysis of 148,000 Delta cases and 68,000 Omicron cases in the UK up to 20 December 2021, it has been published that booster injection protection against symptomatic COVID-19 caused by the Omicron variant seems to wear off in about 10 weeks. Among those who received two doses of the AstraZeneca vaccine, a booster of the Pfizer or Moderna vaccine was $60 \%$ effective in preventing symptomatic disease 2 to 4 weeks after injection. But after 10 weeks, the Pfizer booster was 35\% effective and the Moderna booster was $45 \%$ effective. Among those who received three doses of Pfizer, the vaccine's effectiveness was $70 \%$ about a week after the booster but dropped to $45 \%$ after 10 weeks. At the same time, those who received an initial two-dose series of Pfizer vaccine and then a Moderna booster appeared to be $75 \%$ effective for up to 9 weeks [38]. Beyond protecting against severe forms of the disease, if the effectiveness of current vaccines is not sustained over time and the wave of omicron does not create herd immunity, next-generation vaccines will need to be developed.

\section{Vaccination has contributed to an appreciable reduction in the number of serious and critical clinical cases}

The longing for a decisive solution probably distorts the perception of reality. And, although vaccination has contributed to an appreciable reduction in the number of serious and critical clinical cases, it does not absolutely prevent the spread of the infection, which can also recur without our knowledge to what extent [38]. At this time, we should be able to assess that the increase in infections is not necessarily associated with an increase in clinically serious or critical cases [38]. Omicron evades the immune response and everything indicates that it does not have greater lethality. Those who are vaccinated would still face a world with COVID-19, but for the vast majority, this would have minimal impact. Exposure is most likely to result in mild illness, with the added benefit of increased mucosal immunity. Of course, cases would increase, and severe cases would increase among the unvaccinated [37].

The number of cases observed on the dates this article is written (first days of January 2022) may surprise us as unexpected and confuse us in decisions, so it is better to focus on the severity that this new wave could bring to countries more vaccinated.

Apart from the uncertainty about the true intrinsic severity of the omicron variant, which appears to be less severe [39-41], the good news is that its effects in today's world are much lower, thanks to the combination of vaccination, natural defenses due to previous infections and that possible greater lightness of the virus. Models from the University of Washington estimate that $90 \%$ of omicron cases will be asymptomatic compared to $40 \%$ of the previous variants [42]. The omicron variant infection is less severe in those vaccinated. Delta or omega infection is also less serious. But on the other hand, the risk of becoming infected only clearly decreases among those who 
have three doses. Surely, and due to the mere fact of having a more vaccinated population, those hospitalized will be more frequently vaccinated.

\section{This context may increase denial regarding COVID-19 vaccines}

This scenario can fuel people's denial of the COVID-19 vaccination. Thus, the role of the GP will be especially important in the transmission of scientifically and emotionally appropriate messages, since it can know its patients as people, their needs and desires, their preferences and idiosyncrasies, sometimes their fears and hopes $[43,44]$.

\section{Will incidence rates and diagnostic tests cease to be im- portant?}

Current vaccines with the Omicron variant are not effective enough to prevent infections and transmission, so attack rates in those vaccinated with one or two doses will increase as the proportion of vaccinated increases [13]. Thus, it is very likely that all people on the planet who have not yet been infected or vaccinated will eventually become infected. It is only a matter of time [37]. Thus, collecting data on incidence rates at the community level may no longer be important. In addition, the exponential increase in cases with a very high community transmission de facto prevents, due to the impossibility of resources and due to real utility, the tracing of contacts; what has been officially discontinued in some places, being reserved for some high-risk contacts [45].

With the vaccination dams, we are resisting very hard, but in the end, the tsunami will defeat us. We are all going to infect each other, thus we will obtain our immunity booster against the disease, only patients who arrive at the hospital will be tested. And then the question will arise of vaccinating the elderly and/or people with comorbidities each year with a suitable vaccine, which could even be combined with influenza. It would no longer be a "zero COVID-19" strategy, but rather to live with the endemic disease [46].

The importance does not reside so much in vaccinated, which already seems established that with two doses they notably avoid serious disease, and with three they reduce the risk much more, but with those not vaccinated or vaccinated with a single dose, although also for those where we know that the efficacy of vaccines is lower, such as those over 65 years of age, immunosuppressed and patients with comorbidities [47].

In the first weeks of the year 2022, nothing else is expected then to see how the cases increase. The saturation of health care services is already seen in some places, but the saturation of the centers for conducting diagnostic tests is more marked. Rapid antigen tests could be of great help to decentralize and alleviate this tension. In a patient with symptoms and at times of great viral circulation, such as this one, the probability that if the test is positive the person has the disease is as high as $98 \%$, and although 43 out of every 1,000 tests may be false negatives, surely always believing in the test result seems to be advantageous. It may be different in asymptomatic patients, but even in this group the positive predictive value of an antigen test also exceeds $98 \%$, but 10 out of 100 patients may have a false negative. The provision of tests for the same people to detect themselves is something that is done in the United Kingdom, the United States, and Europe. But, compared to its advantages, there are its disadvantages: traceability or epidemiological monitoring of COVID-19 will be lost [47]. On the other hand, and last but not least, is the task of attending to Long COVID-19 $[48,49]$.

\section{Conclusion}

The effectiveness of vaccines has changed dramatically in the Omicron era. This situation originates certain effects at the community level and has certain implications for the general practitioner (Table 1): 1 . The availability of vaccines has brought about a change that, when they began to be applied, seemed much more promising than it is currently; 2. This context may increase the denial of vaccines against COVID-19; 3. Vaccination has contributed to a significant decrease in the number of serious and critical clinical issues; 4. Attack rates in vaccinated will increase as the proportion of vaccinated increases; 5. The importance of booster doses; 6 . Incidence rates at the community level and official diagnostic tests will no longer be important. The general practitioner should reflect on these effects of the evolution of COVID-19 and propose actions at their work level in relation to them.

\section{References}

1. McNamara D (2021) COVID-19, Sure, but What Else Will We Remember 2021 For? Medscape. Link: https://wb.md/3qKgtfr

2. Pérez-Cortés Villalobos A (2021) A new disease that we must know: Covid-19 after being vaccinated. Medscape. Link: https://bit.ly/3ICNdgT

3. Wallace-Wells B (2021) My Family Was a COVID Cluster. Four vaccinated adults and two unvaccinated children had mild symptoms. Is this what the end of the pandemic looks like? The New Yorker. Link: https://bit.ly/3GMF1K

4. Lucas C, Vogels CBF, Yildirim I, Rothman JE, Lu P, et al. (2021) Impact of circulating SARS-CoV-2 variants on mRNA vaccine-induced immunity. Nature 600: 523-529. Link: https://bit.ly/3qMAlsZ

5. Slotnik DE (2021) A W.H.O. panel recommends additional vaccine doses for immunocompromised people. The New York Times. Link: https://nyti.ms/3tOEAeZ

6. Levin EG, Lustig y, Cohen C, Fluss R, Indenbaum I, et al. (2021) Waning immune humoral response to BNT162b2 Covid-19 vaccine over 6 months. N Engl J Med 385: e84. Link: https://bit.ly/3tIDXTT

7. Tartof SY, Slezak JM, Fischer H, Hong V, Ackerson BK, et al. (2021) Effectiveness of mRNA BNT162b2 COVID-19 vaccine up to 6 months in a large integrated health system in the USA: A retrospective cohort study. Lancet 398 1407-1416. Link: https://bit.ly/3nH7R7q

8. Chemaitelly H, Tang P, Hasan MR, AlMukdad S, Yassine HM, et al. (2021) Waning of BNT162b2 vaccine protection against SARS-CoV-2 infection in Qatar. N Engl J Med 385: e83. Link: https://bit.ly/3nHzSvk

9. Coronavirus Resource Center (2022) Johns Hopkins University \& Medicine. Link: https://bit.ly/3qKbUS

10. Oliveres $\vee(2021)$ The world records the largest number of contagions of Covid-19 in a week. ElDiario.es. Link: https://bit.ly/3AgsKeA 
11. Elliott $P$, Bodinier B, Eales $O$, et al. (2021) Rapid increase in Omicron infections in England during December 2021: REACT-1 study. MedRxiv. Link: https://bit.ly/3AeRRi2

12. Gerli AG, Centanni S, Soriano JB, Ancochea J (2021) Forecasting COVID-19 infection trends and new hospital admissions in England due to SARS-CoV-2 Variant of Concern Omicron. MedRxiv. Link: https://bit.ly/3KszpH9

13. Roa R (2021) Sobre la levedad de omicron. La biblioteca de Springfield. Link: https://bit.ly/3tDkd4e

14. Turabian JL (1995) Notebooks of Family and Community Medicine. An introduction to the principles of Family Medicine. Madrid Díaz de Santos.

15. Turabian JL (2017) Fables of Family Medicine. A collection of fables that teach the Principles of Family Medicine. Saarbrücken, Deutschland/Germany: Editorial Académica Española. Link: https://bit.ly/3Ajn57r

16. Turabian JL (2017) Stories Notebook about the Fundamental Concepts in Family Medicine: An Introduction. J Gen Pract (Los Angel); 5: 283. Link: https://bit.ly/3tJrQGr

17. They did not Expect Him.jpg (2021) Wikimedia Commons. Link: https://bit.ly/3qJMows

18. Mandavilli A (2021) Why Vaccinated People Are Getting 'Breakthrough' Infections. The vaccines are effective at preventing serious illness and death, but they are not a golden shield against the coronavirus. The New York Times. Link: https://nyti.ms/3tHdndQ

19. Keehner J, Horton LE, Pfeffer MA, et al. (2021) SARS-CoV-2 Infection after Vaccination in Health Care Workers in California. N Engl J Med 384: 17741775. Link: https://bit.ly/3GQVwF9

20. Thompson MG, Burgess JL, Naleway AL, Tyner H, Yoon SK, et al. (2021) Prevention and attenuation of Covid-19 with the BNT162b2 and mRNA-1273 vaccines. N Engl J Med 385: 320-329. Link: https://bit.ly/3KsztXp

21. Kerwin H, Briggs R, Nair-Desai S, Gorzalski A, Pandori M, et al. (2021) An Analysis of SARS-CoV-2 Vaccine Breakthrough Infections and Associated Clinical Outcomes. MedRxiv. Link: https://bit.ly/3fJnero

22. Cuppini $L$ (3021) What happens when you contain Covid being vaccinated?. E Mundo; Actualizado Martes, 3 agosto. Link: https://bit.ly/33NTAi6

23. Antonelli A, Penfold RS, Merino J, Sudre CH, Molteni E, et al. (2021) Risk factors and disease profile of post-vaccination SARS-CoV-2 infection in UK users of the COVID Symptom Study app: a prospective, community-based, nested, case-control study. Lancet Infect Dis 22: 43-55. Link: https://bit.ly/3tKmsCY

24. Kustin T, Harel N, Finkel U, Perchik S, Harari S, et al. (2021) Evidence for increased breakthrough rates of SARS-CoV-2 variants of concern in BNT162b2-mRNA-vaccinated individuals. Nat Med 27: 1379-1384. Link: https://bit.ly/3KmlC5b

25. Santucci J (2021) Vaccines cut chances of long COVID in half, study shows; millions of Americans keep vaccination secret: COVID-19 updates. USA Today.

26. Bergwerk M, Gonen T, Lustig Y, Amit S, Lipsitch M, et al. (2021) Covid-19 Breakthrough Infections in Vaccinated Health Care Workers. N Engl J Med 385: 1474-1484. Link: https://bit.ly/3Is1Bsd

27. Turabian JL (2022) Risk factors and incidence rates of COVID-19 breakthrough infections in vaccinated people in general medicine practice in Toledo (Spain) Archives of Family Medicine and General Practice. In Press.

28. CDC COVID-19 Vaccine Breakthrough Case Investigations Team (2021) COVID-19 vaccine breakthrough infections reported to CDC - United States. MMWR Morb Mortal Wkly Rep 70: 792. Link: https://bit.ly/3FOEOF0

29. White EM, Yang X, Feifer RA, Gravenstein S, Mor V (2021) Incident SARSCoV-2 Infection among mRNA-Vaccinated and Unvaccinated Nursing Home Residents. N Engl J Med 385: 474-476. Link: https://bit.ly/3FLdVSn
30. Keehner J, Horton LE, Binkin NJ, Laurent LC, Pride D, et al. (2021) Resurgence of SARS-CoV-2 Infection in a Highly Vaccinated Health System Workforce. N Engl J Med 14. Link: https://bit.ly/3rzVsTR

31. Mahase E (2021) Covid-19: Most people admitted to hospital after vaccination were infected before immunity could develop, research shows. BMJ 373 n1127. Link: https://bit.ly/3GLEWGT

32. Ramirez E, Wilkes RP, Carpi G, Dorman J, Bowen C, et al. (2021) SARS-CoV-2 Breakthrough Infections in Fully Vaccinated Individuals. MedRxiv. Link: https://bit.ly/359vL55

33. Nemet I, Kliker I, Lustig Y (2021) Third BNT162b2 Vaccination Neutralization of SARS-CoV-2 Omicron Infection. N Engl J Med. Link: https://bit.ly/3AfIrTn

34. Collie S, Champion J, Moultrie H, Bekker LG, Gray G (2021) Effectiveness of BNT162b2 Vaccine against Omicron Variant in South Africa. N Engl J Med. Link: https://bit.ly/3fFA1uS

35. Yoshikura H (2021) Epidemic Curves of COVID-19 Unaffected by Vaccination Epidemol Int J 5: 000209. Link: https://bit.ly/3G07cID

36. Simó J (2021) This has to stop! Stop doing to be able to do. Salud, dinero y atención primaria; Domingo. Link: https://bit.ly/3GNXtCa

37. Wilson FP (2021) The Pandemic Isn't Over Until We Stop Isolating People for COVID. Medscape. Link: https://wb.md/3FKziTY

38. Crist C (2021) COVID Booster Protection May Wane in About 10 Weeks, New Data Show. Medscape. Link: https://wb.md/3KvMJKU

39. Segura A (2021) Another (plausible) account of the pandemic is possible Salud, dinero y atención primaria: Viernes, 31 de Diciembre. Link: https://bit.ly/34XyZZa

40. Jassat W, Karim SA, Mudara C, Welch R, Ozougwu L, et al. (2021) Clinical Severity of COVID-19 Patients Admitted to Hospitals in Gauteng, South Africa During the Omicron-Dominant Fourth Wave. Preprints The Lancet. Link: https://bit.ly/3nlx|4e

41. Wolter N, Jassat W, Walaza S, Welch R, Moultrie H, et al. (2021) Early assessment of the clinical severity of the SARS-CoV-2 Omicron variant in South Africa. MedRxiv. Link: https://bit.ly/3fJbZzs

42. Sheikh A, Kerr S, Woolhouse M, McMenamin J, Robertson C (2021) Severity of omicron variant of concern and vaccine effectiveness against symptomatic disease: national cohort with nested test negative design study in Scotland The University od Edimburgh. Link: https://bit.ly/3tHQRBH

43. Gray GE, Collie S, Garrett N, Goga A, Champion J, et al. (2021) Vaccine effectiveness against hospital admission in South African health care workers who received a homologous booster of Ad26.COV2 during an Omicron COVID19 wave: Preliminary Results of the Sisonke 2 Study. MedRxiv. Link: https://bit.ly/3GQVWeH

44. Geng EH (2022) The Doctor's Oldest Tool. N Engl J Med 386: 7-9. Link: https://bit.ly/3qHNR6v

45. Rittenberg E (2022) Trust, Faith, and Covid. N Engl J Med 385: 2504-2505 Link: https://bit.ly/33DIM7v

46. Dirección General de salud Pública. Consejería de Sanidad de Castilla-La Mancha (2021) Adaptation of the strategy for early detection, surveillance and control of COVID-19 in period of high community transmission. Comisión de Salud Pública. Link: https://bit.ly/3Kw47PJ

47. Lecrubier A (2021) Decline in effectiveness of boosters in the face of the Omicron wave: should the vaccine strategy be reviewed?. Medscape.

48. Roa R (2022) Week 1, evolution of the pandemic. La biblioteca de Springfield; 2 de enero. Link: https://bit.ly/3KszOJF

49. Turabian JL (2021) Implications for the General Practitioner of Long Covid Syndrome. Int Res Med Health Sci: 1-13. Link: https://bit.ly/3AgKkza

Citation: Turabian JL (2022) Implications for general practitioner of evolution of incidence rates of CoVID-19 breakthrough infections in vaccinated people as of December 2021 with the highest spike of infections of the entire pandemic. Arch Community Med Public Health 8(1): 008-012. DOI: https://dx.doi.org/10.17352/2455-5479.000168 